\title{
Modulation of L-Selectin Ligand Expression during an Immune Response Accompanying Tumorigenesis in Transgenic Mice
}

\author{
Susan V. Onrust, Philippe M. Hartl, ${ }^{\star}$ Steven D. Rosen, and Douglas Hanahan* \\ Department of Anatomy and Program in Immunology, *Hormone Research Institute, and *Department of Biochemistry and Biophysics, \\ University of California, San Francisco, California 94143
}

\begin{abstract}
Immune surveillance depends on lymphocyte access to tissue. Lymphocytes emigrate from blood when adhesion receptors such as L-selectin and the $\alpha_{4} \beta_{7}$ integrin on these cells bind to ligands expressed on venular endothelium. Among transgenic mouse lines expressing an oncoprotein (Tag) in islet $\beta$ cells, some recognize Tag as nonself. In these mice, Tag expression elicits both $\beta$ cell hyperplasia with subsequent progression to tumors and lymphocytic infiltration. Endothelial ligands for L-selectin and $\alpha_{4} \beta_{7}$ were upregulated in infiltrated islets in these transgenic mice. These ligands were not expressed in tumors, which were devoid of lymphocytic infiltration. In contrast, the adhesion molecules PECAM-1, ICAM-1, and VCAM-1 were expressed on endothelium in both noninfiltrated tumors and infiltrated islets. Thus, upregulation of expression of endothelial ligands for L-selectin and $\alpha_{4} \beta_{7}$ may contribute to autoimmune infiltration. Repression of expression of these same ligands may be involved in the failure of tumor immunity. (J. Clin. Invest. 1996. 97:54-64.) Key words: inflammation - vascular addressin • L-selectin • MAdCAM-1 • tumor progression
\end{abstract}

\section{Introduction}

Lymphocytes continually move from blood to secondary lymphoid organs such as lymph nodes and Peyer's patch, and back to blood. Lymphocytes exit the blood at specialized high endothelial postcapillary venules $(\mathrm{HEV})^{1}$ in these tissues (1). At sites of chronic inflammation, HEV-like vessels are often induced and allow large numbers of lymphocytes to emigrate from blood and accumulate in extralymphoid tissues $(2,3)$.

Address correspondence to Steven D. Rosen, Ph.D., Dept. of Anatomy, University of California, 513 Parnassus Avenue, San Francisco, CA 94143-0452. Phone: 415-476-1579; FAX: 415-476-4845; E-mail: sdr@itsa.ucsf.edu Susan V. Onrust's current address is SUGEN, Inc., 515 Galveston Drive, Redwood City, CA 94063.

Received for publication 22 January 1995 and accepted in revised form 11 September 1995.

1. Abbreviations used in this paper: CM, conditioned medium; HEV, high endothelial postcapillary venules; LEC-IgG, L-selectin-IgG chimera; MAdCAM-1, mucosal addressin cell adhesion molecule-1; NOD, nonobese diabetic; PNAd, peripheral lymph node addressin; RIP, rat insulin gene promoter; Tag, simian virus 40 large $\mathrm{T}$ antigen.

J. Clin. Invest.

(C) The American Society for Clinical Investigation, Inc.

0021-9738/96/01/54/11 \$2.00

Volume 97, Number 1, January 1996, 54-64
Lymphocyte extravasation involves a series of regulated, adhesive interactions between receptors on the blood-borne lymphocyte and ligands on HEV in lymphoid tissues. The first of these interactions causes the lymphocyte to roll along the vessel wall (4). Within seconds, the rolling lymphocyte becomes firmly adherent, and the lymphocyte transmigrates from the blood vessel to tissue.

Endothelial adhesion molecules and lymphocyte receptors involved in each of the steps of lymphocyte extravasation to lymphoid tissues are listed in Table I. L-Selectin ligands and mucosal addressin cell adhesion molecule-1 (MAdCAM-1) mediate rolling (5-7) and are recognized by the lymphocyte receptors L-selectin (peripheral lymph node homing receptor, gp90 $0^{\mathrm{MEL}}$, LECAM-1, LAM-1, CD62L) and $\alpha_{4} \beta_{7}$ (Peyer's patch homing receptor, $\alpha_{4} \beta_{\mathrm{P}}$, LPAM-1), respectively. The L-selectin ligands and MAdCAM-1 were originally identified as endothelial molecules which permit lymphocyte homing to particular lymphoid organs, and were thus termed "vascular addressins" (8, 9). MAdCAM-1 is an unusual cell-surface, transmembrane protein with both immunoglobulin superfamily and mucin-like domains (10). Normally, this protein's expression is restricted to Peyer's patch HEV, mesenteric lymph node HEV, lamina propria of the gut, and lactating mammary gland. MAdCAM-1 expression is also constitutively present on occasional blood vessels in the exocrine tissue of the pancreas $(8,11)$.

The lymphocyte receptor L-selectin is a protein with homology to C-type lectins $(12,13)$ and functions through calcium-dependent recognition of specific carbohydrate structures on a discrete set of endothelial glycoprotein ligands (1416). In particular, L-selectin recognizes sulfate, sialic acid, and fucose, which may be presented in capping groups as sialyl Lewis $\mathrm{x}$ containing galactose-6-sulfate or $\mathrm{N}$-acetyl glucosamine-6-sulfate $(15,17-20)$. Several endothelial ligands for L-selectin have been identified on lymph node HEV, including the mucin-like proteins GlyCAM-1 and CD34 (21, 22), Sgp200 (a sulfated glycoprotein of $200 \mathrm{kD}$ [23]), and a subset of MAdCAM-1 molecules (5). In addition to lymph node HEV, GlyCAM-1 is normally expressed by mammary gland epithelial cells $(21,24)$, and CD34 is widely expressed on vascular endothelium and hematopoietic stem cells $(25,26)$. However, the GlyCAM-1 and CD34 molecules in lymph node HEV are selectively modified with the carbohydrate structure recognized by L-selectin. While MAdCAM-1 serves as a ligand for $\alpha_{4} \beta_{7}$, a subset of the MAdCAM-1 molecules synthesized in mesenteric lymph nodes also binds L-selectin (5), and, presumably, this subset also carries the appropriate carbohydrate modification on the protein's mucin-like domain. In mesenteric lymph nodes, L-selectin ligands and MAdCAM-1 are both expressed on HEV, thus both L-selectin- and $\alpha_{4} \beta_{7}$-bearing lymphocytes can enter this tissue from blood $(9,27)$. The core protein of Sgp200 has not yet been identified.

Two mAb have been used extensively to identify L-selectin 
Table I. Endothelial Adhesion Molecules and Lymphocyte Receptors

\begin{tabular}{llcc}
\hline Endothelial adhesion molecule & Detected with: & Expression & Lymphocyte receptor \\
\hline $\begin{array}{l}\text { L-Selectin ligands: } \\
\text { GlyCAM-1 }\end{array}$ & LEC-IgG, MECA 79 mAb* & Lymph node HEV & L-Selectin \\
CD34 & & & \\
Sgp200 & MECA 367 mAb & Peyer's patch HEV, mesenteric & $\alpha_{4} \beta_{7}$ integrin \\
MAdCAM-1 & PECAM-1 mAb & lymph node HEV & PECAM-1 \\
PECAM-1 (CD31) & ICAM-1 mAb & B lymphocytes & \\
ICAM-1 & Blood vessel endothelium, & T lymphocytes & $\alpha_{\mathrm{L}} \beta_{2}$ integrin (LFA-1, \\
VCAM-1 & Blood vessel endothelium & $\alpha_{4} \beta_{1}$ integrin (VLA-4) \\
\hline
\end{tabular}

* MECA 79 recognizes a group of lymph node HEV antigens referred to as PNAd (9). In the mouse, these antigens include the L-selectin ligands GlyCAM-1, CD34, and Sgp200 and possibly other molecules $(5,16,23)$. ${ }^{\ddagger}$ Berg et al. (5) showed that a fraction of MAdCAM-1 molecules expressed on mesenteric lymph node HEV is recognized by MECA 79 and L-selectin in addition to MECA 367. This presumably results from a subset of MAdCAM-1 molecules carrying the appropriate carbohydrate structure on its mucin-like domain.

ligands and MAdCAM-1. The MECA 79 mAb stains lymph node HEV selectively and blocks L-selectin binding (9) through recognition of a critical portion of the carbohydrate structure seen by L-selectin (23). The group of glycoproteins recognized by MECA 79 has been collectively termed peripheral lymph node addressin (PNAd) (9). In lymph node lysates, MECA 79 recognizes the L-selectin ligands GlyCAM-1, CD34, Sgp200, a subset of MAdCAM-1 molecules, and possibly additional species $(5,16,23)$. In this report, the term PNAd is used to refer to those molecules bearing the MECA 79 epitope, while L-selectin ligand is reserved for molecules known to be recognized by L-selectin. In contrast to MECA 79, the MECA $367 \mathrm{mAb}$ stains mucosal and mesenteric lymph node HEV selectively and blocks $\alpha_{4} \beta_{7}$-mediated binding $(6,8,10)$. The target of MECA 367 is a protein-based epitope on MAdCAM-1 (10).

PNAd and MAdCAM-1, as defined by MECA 79 and MECA 367 reactivity, respectively, are induced on endothelium at a number of sites of chronic inflammation (11, 28-33). L-Selectin and $\alpha_{4} \beta_{7}$ have been shown to play a role in lymphocyte recruitment to some of these sites $(11,34)$. For example, both PNAd and MAdCAM-1 are expressed at high levels on HEV-like vessels induced in pancreatic islets during autoimmune inflammation in nonobese diabetic (NOD) mice (11, 30). The counterpart homing receptors L-selectin and $\alpha_{4} \beta_{7}$ are functionally important, because in vivo administration of antiL-selectin or anti- $\alpha_{4}$ antibodies reduces islet infiltration and the incidence of diabetes (34). Notably, the L-selectin ligands expressed at these inflammatory sites have not heretofore been defined at the biochemical level, although GlyCAM-1 expression was identified recently by immunohistochemical techniques in infiltrated islets in NOD mice (25).

Distinct from L-selectin ligands and MAdCAM-1 are the endothelial adhesion molecules ICAM-1 and VCAM-1, which are recognized by the leukocyte integrins $\alpha_{L} \beta_{2}$ (LFA-1, CD11/CD18) and $\alpha_{4} \beta_{1}$ (VLA-4), respectively. ICAM-1 is involved in firm adhesion (35), whereas VCAM-1 may participate in rolling as well as firm adhesion (36). Another endothelial adhesion molecule, PECAM-1 (CD31), is important in transmigration of neutrophils and monocytes and may play a similar role in lymphocyte transmigration (37). Unlike L-selec- tin ligands and MAdCAM-1, the adhesion molecules ICAM-1, VCAM-1, and PECAM-1 are each widely expressed on vascular endothelium (for reviews see references 38-40).

To study the potential role of vascular addressins in an autoimmune inflammatory response and tumorigenesis, we examined pancreatic islets in transgenic mice expressing the oncoprotein Tag (simian virus 40 large $\mathrm{T}$ antigen) under control of the rat insulin gene regulatory region (RIP, RIP-Tag mice). In these mice, Tag expression in the insulin-producing $\beta$ cells of the pancreatic islets results in hyperplasia of the islets, followed by development of solid tumors (insulinomas) and finally, premature death (41). Tag is recognized as a self protein in tolerant lines typified by RIP1-Tag2 $(41,42)$, which begin to express the protein during embryonic development (43). In nontolerant lines such as RIP1-Tag3 $(42,44)$ and RIP1-Tag5 (Jolicoeur, C., K. Smith, J. Skowronski, and D. Hanahan, unpublished observations), the onset of Tag expression is delayed until 10-12 wk of age, probably due to differences in the site of integration of the transgene (45). There is a failure of self-tolerance, and these animals recognize Tag as a nonself protein. A consequence of nonself recognition of Tag is an intense infiltration of the hyperplastic islets, consisting of $\mathrm{CD}^{+}$ and $\mathrm{CD}^{+} \mathrm{T}$ cells, B cells, and macrophages (44). Similar numbers of macrophages, but only rare lymphocytes, are detected in islets of RIP1-Tag2 mice, suggesting that Tag-reactive lymphocytes are required for inflammation (Jolicoeur, C., and D. Hanahan, unpublished observations). The appearance of autoantibodies against Tag and the identification of anti-Tag cytotoxic and helper $\mathrm{T}$ cells within islets of nontolerant animals suggest that, as in diabetes, $\beta$ cells are being attacked $(42,46)$.

Of interest, RIP-Tag mice do not develop diabetes. Instead, both tolerant and nontolerant RIP-Tag mice succumb to $\beta$ cell tumors, which develop from hyperplastic islets as a consequence of Tag expression (41). In striking contrast to the infiltrated hyperplastic islets, tumors which develop in nontolerant transgenic mice are essentially devoid of lymphocytes, although they continue to express Tag and are highly vascularized.

In this report, we show that the inflammatory response to 
Tag is correlated with induction of PNAd, MAdCAM-1, and VCAM-1 expression on blood vessel endothelium in islets. Further, we demonstrate directly that endothelial ligands for L-selectin are induced on vessels in infiltrated islets and identify one of these ligands as GlyCAM-1. Finally, no PNAd or MAdCAM-1 expression could be detected within the $\beta$ cell tumors, though vessels within tumors expressed readily detectable levels of PECAM-1, ICAM-1, and VCAM-1. The failure to express vascular addressins on tumor vessels may contribute to the exclusion of lymphocytes and may result in evasion of immune-mediated tumor destruction.

\section{Methods}

Mice. The construction of the RIP1-Tag hybrid gene and generation of the RIP1-Tag2 transgenic lineage have been described (41). The RIP1-Tag5 line was produced in the $\mathrm{C} 3 \mathrm{Heb} / \mathrm{FeJ}(\mathrm{C} 3 \mathrm{H})$ background. The phenotype of RIP1-Tag5 mice (Jolicoeur, C., and D. Hanahan, unpublished observations) is virtually identical to that reported for the RIP1-Tag3 line $(41,42,44)$. The RIP1-Tag2 line used here was generated in the B6D2F1 background and backcrossed to $\mathrm{C} 3 \mathrm{Heb} / \mathrm{FeJ}$ mice for at least 12 generations. RIP1-Tag5, RIP1-Tag2, and nontransgenic $\mathrm{C} 3 \mathrm{H}$ mice were maintained in a barrier facility and fed a normal diet.

Reagents. Anti-mouse VCAM-1 (rat IgG2a) and anti-mouse PECAM-1 (rat IgG2a) mAb were purchased from Pharmingen (San Diego, CA). Anti-mouse ICAM-1 (rat IgG2a) mAb was purchased from Caltag Laboratories (San Francisco, CA). Purified MECA 79 (rat $\operatorname{IgM}$ ) and MECA 367 (rat $\operatorname{IgG2a}$ ) mAb $(8,9)$ were kindly provided by E. C. Butcher (Stanford University, Stanford, CA). An IgM antibody against an irrelevant antigen (Pharmingen) was used as a class-matched control antibody for MECA 79 immunoprecipitations. Anti-CD4 (rat IgG2b) and anti-B220 (rat IgG2a) mAb were prepared as ascites fluid with hybridomas GK1.5 and RA3-6B2, respectively, obtained from the American Type Culture Collection (Rockville, MD). The rabbit antipeptide antibody against mouse GlyCAM-1 has been described (peptide 2 in reference 21) and was affinity-purified and generously provided by M. S. Singer (UCSF). Affinity-purified rabbit anti-mouse CD34 (22) was kindly provided by S. Baumhueter (Genentech Inc., South San Francisco, CA). The LEC-IgG protein, consisting of the extracellular domain of mouse L-selectin joined to the constant region of human IgG1, has been described (46) and was kindly provided by S. Watson and L. Lasky (Genentech Inc.).

Histological methods. Histochemical staining shown in Fig. 1 was done on $10-\mu \mathrm{m}$ cryostat sections of pancreata fresh frozen on dry ice in optimal cooling temperature compound, i.e., O.C.T. (Miles Laboratories Inc., Elkhart, IN). Sections were air dried for $1 \mathrm{~h}$, fixed for $5 \mathrm{~min}$ with ice-cold acetone, and then air dried for at least $15 \mathrm{~min}$. After incubation for $30 \mathrm{~min}$ at room temperature in blocking solution ( $5 \%$ goat serum, $0.5 \%$ BSA in PBS), fixed sections were reacted for $1 \mathrm{~h}$ with $20 \mu \mathrm{g} / \mathrm{ml}$ primary antibody in blocking solution. Primary antibody was detected with biotinylated rabbit anti-rat IgG (mouse adsorbed) (Vector Laboratories, Burlingame, CA) in blocking solution and color was developed with ABC-horseradish peroxidase (Elite kit; Vector Laboratories) and AEC chromogen (Biomeda, Foster City, CA). Hematoxylin was used as a counterstain.

For histochemistry shown in Fig. 2, animals were heart-perfused with PBS containing $4 \%$ paraformaldehyde, then pancreata were removed and embedded in paraffin. $10-\mu \mathrm{m}$ sections were deparaffinized and treated with Antigen Retrieval Citra (BioGenex Labs, San Ramon, CA) and then blocked for $30 \mathrm{~min}$ at room temperature with $10 \%$ goat serum and $1 \%$ BSA in PBS. Sections to be stained with LEC-IgG were further treated for $30 \mathrm{~min}$ at $4^{\circ} \mathrm{C}$ with $5 \mathrm{mM}$ sodium periodate to enhance staining intensity, as described (47). Primary antibody (MECA 79, $5.6 \mu \mathrm{g} / \mathrm{ml}$; affinity-purified anti-GlyCAM-1, $3.2 \mu \mathrm{g} / \mathrm{ml})$ or LEC-IgG $(25 \mu \mathrm{g} / \mathrm{ml})$ was diluted in PBS containing $5 \%$ goat serum and $0.5 \%$ BSA, and incubation was at $4{ }^{\circ} \mathrm{C}$ overnight. Secondary antibody was biotinylated rabbit anti-rat IgG (mouse adsorbed) (Vector Laboratories) for MECA 79, biotinylated goat anti-human $\operatorname{IgG}\left(\mathrm{F}(\mathrm{ab})_{2}\right.$ fragment; Caltag Laboratories) for LEC-IgG, or biotinylated goat anti-rabbit IgG (Vector Laboratories) for anti-GlyCAM-1. Color development utilized ABC-alkaline phosphatase and alkaline phosphatase Substrate Kit I (Vector Laboratories), and hematoxylin was used as a counterstain. MECA 367 did not stain vessels in paraffin sections.

Isolation of islets, tumors, and lymph nodes. Preparation of hyperplastic islets and $\beta$ cell tumors for biochemical experiments was based on a published procedure (48). The pancreas of each RIP1-Tag mouse killed by cervical dislocation was perfused via the common bile duct with $3 \mathrm{ml}$ of HBSS containing $1.162 \mathrm{mg} / \mathrm{ml}$ collagenase $\mathrm{P}$ (Boehringer Mannheim, Indianapolis, IN) and was then removed from the animal. The pancreas was placed in $2 \mathrm{ml}$ ice-cold HBSS and incubated at $37^{\circ} \mathrm{C}$ for $19 \mathrm{~min}$. Then, $5 \mathrm{ml}$ cold HBSS was added, contents were mixed, and tissue was filtered through 524- $\mu$ m nylon mesh (Spectrum Medical Industries, Inc., Houston, TX). The flow-through, which consisted of loose islets, ductule and exocrine tissue, and rare pancreatic lymph nodes, was washed with ice-cold HBSS containing $10 \%$ FBS (Gibco Laboratories, Grand Island, NY) three times by centrifugation for $4 \mathrm{~min}$ at $200 \mathrm{~g}$. Hyperplastic islets were identified, distinguished from pancreatic lymph nodes under a dark-field dissecting microscope based on shape, color, vascularization, and association with ductule tissue, and were individually pipetted to a separate dish. Tumors were usually retained by the nylon mesh and were easily identified by size, opacity, extensive vascularization, and the presence of a well-formed capsule. They were also collected after carefully trimming away occasional associated islets and lymph nodes. Axillary, brachial, and mesenteric lymph nodes were removed from the same mice or from 8-12-wk-old female ICR mice and were minced finely with razor blades. No obvious differences were observed between RIP1-Tag, nontransgenic C3H, and ICR mouse lymph nodes.

Northern analysis. Total cellular RNA was prepared from isolated lymph nodes, islets, and tumors by the guanidinium-phenol method (49). $5 \mu \mathrm{g}$ RNA (based on absorbance at $260 \mathrm{~nm}$ ) per lane was fractionated on a $1.2 \%$ agarose-formaldehyde gel and transferred to nitrocellulose (Schleicher \& Schuell, Inc., Keene, NH). Before transfer, gels were stained with ethidium bromide to ensure that RNA was intact and that approximately equal amounts were loaded in each lane. cDNAs were random-primed labeled with $\left[\alpha{ }^{32} \mathrm{P}\right] \mathrm{dATP}$ (Amersham, Arlington Heights, IL) using the Multiprime DNA Labeling System (Amersham). Prehybridization and hybridization were at $42^{\circ} \mathrm{C}$ in buffer containing $50 \%$ formamide (50). Hybridized filters were washed at high stringency $\left(65^{\circ} \mathrm{C}, 0.25 \times \mathrm{SSC}, 0.2 \% \mathrm{SDS}\right)$ and $\mathrm{ex}-$ posed to film at $-80^{\circ} \mathrm{C}$ with an intensifying screen. To ensure that equal amounts of RNA were loaded in each lane, filters were rehybridized with a random-primed labeled $\beta$-actin cDNA.

Mouse GlyCAM-1 cDNA (21) was provided by D. Dowbenko and human $\beta$-actin cDNA was provided by A. Weiss (UCSF).

Metabolic labeling and immunoprecipitation. Isolated intact islets or tumors, or minced lymph nodes were metabolically labeled in 0.5 $\mathrm{ml}$ sulfate-free RPMI 1640 (Gibco Laboratories) containing 10\% dialyzed FBS and $500 \mu \mathrm{Ci} / \mathrm{ml}\left[{ }^{35} \mathrm{~S}\right]$ sodium sulfate (carrier-free, $43 \mathrm{Ci} / \mathrm{mg}$ sulfur; ICN Biomedicals, Inc., Costa Mesa, CA) for $5.5 \mathrm{~h}$ in a $37^{\circ} \mathrm{C}$, $5 \% \mathrm{CO}_{2}$ incubator. Conditioned medium (CM) was collected, and lysates were prepared by washing tissues well with ice-cold PBS, followed by homogenization in $2 \%$ Triton X-100 in PBS containing protease inhibitors (aprotinin and PMSF, $0.5 \%$ and $1 \mathrm{mM}$ final concentration, respectively). Protease inhibitors were added to $\mathrm{CM}$ also, then $\mathrm{CM}$ and lysates were clarified by centrifugation for $10 \mathrm{~min}$ at $4^{\circ} \mathrm{C}$ at top speed in a microcentrifuge. Protein content of lysates was determined with the micro BCA assay (Pierce, Rockford, IL) using BSA as a standard, and volume of CM used in experiments was based on the protein content of the corresponding lysate. Typically, each mouse yielded $0.5-1 \mathrm{mg}$ islet and $1-3 \mathrm{mg}$ tumor lysate protein.

Samples of CM corresponding to $1 \mathrm{mg}$ lysate protein were ana- 

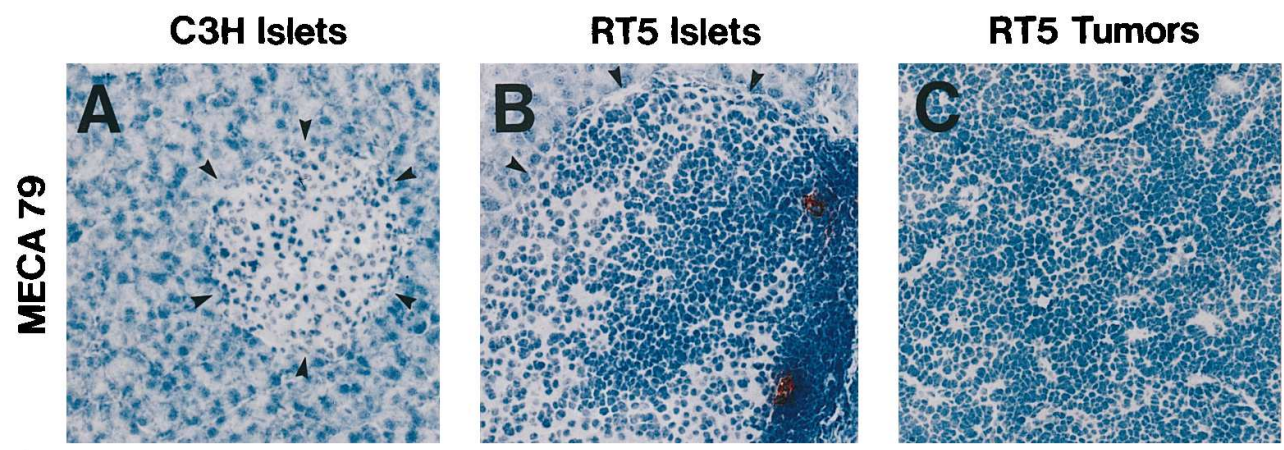

Figure 1. Induction of vascular addressin expression within infiltrated hyperplastic islets, but not within tumors. Immunohistochemical staining of cryostat sections cut from pancreata shows that the vascular addressins PNAd (detected with the $\mathrm{mAb}$ MECA 79) and MAdCAM-1 (detected with the mAb MECA 367) were expressed on blood vessel endothelium within infiltrated islets from nontolerant RIP1-Tag5
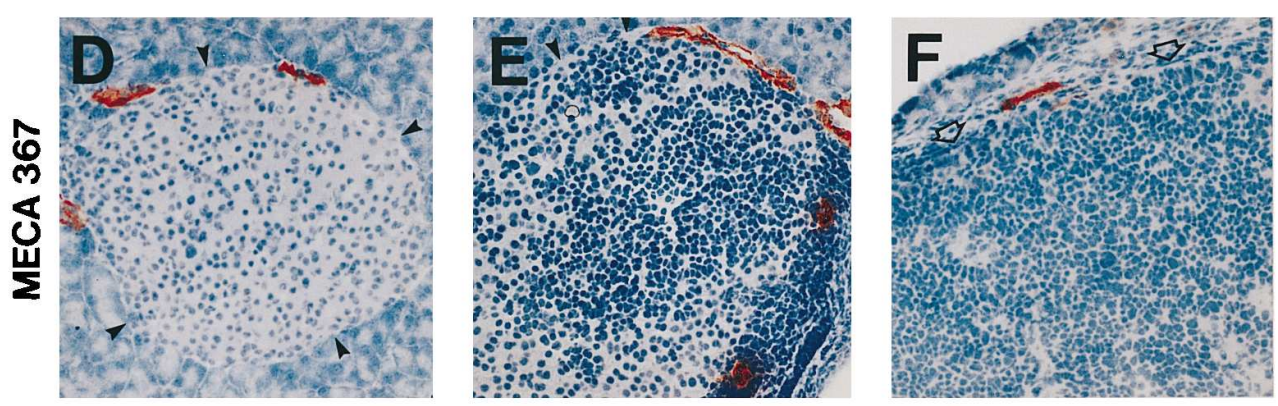
mice (RT5 Islets), but never within nontransgenic, normal $\mathrm{C} 3 \mathrm{H}$ mouse islets ( $\mathrm{C} 3 \mathrm{H}$ Islets) or RIP1-Tag5 tumors (RT5 Tumors). In contrast, the endothelial adhesion molecules PECAM-1, ICAM-1, and VCAM-1 were widely expressed on vessels in tumors and/or noninfiltrated islets. $A-C$ : MECA 79 immunoreactivity was never detected in $\mathrm{C} 3 \mathrm{H}$ pancreas $(A)$, but was present in
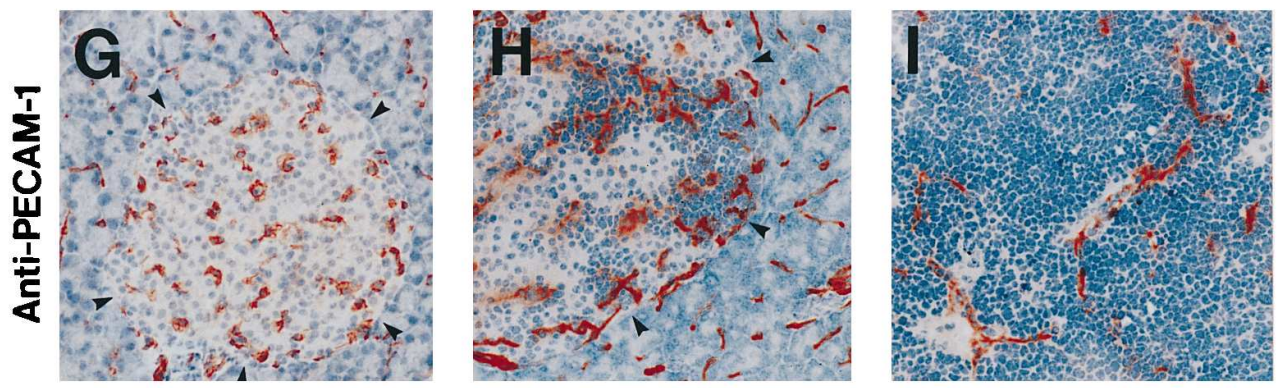
many RIP1-Tag5 islets, where it was restricted exclusively to areas of infiltration $(B)$. RIP1-Tag5 tumors, in contrast, had no MECA 79-positive vessels $(C) . D-F$ : MECA 367 immunoreactivity was frequently present on endothelium in exocrine tissue and at the periphery of, but never within, noninfiltrated control $\mathrm{C} 3 \mathrm{H}$ islets (D). However, MECA 367-positive vessels were present within infiltrated RIP1-Tag5 islets $(E)$,
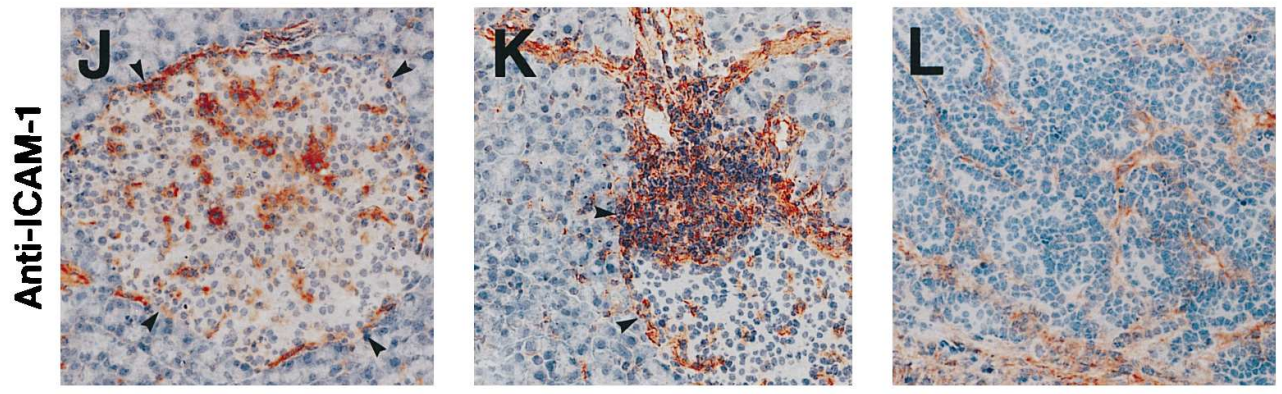
but only in areas of infiltration. Serial sections of the same RIP1Tag5 islet are shown in $B$ and $E$ to illustrate the presence of both MECA 79 and MECA 367 reactivity, respectively, on the same vessels within an area of infiltration. In contrast to infiltrated islets, no MECA 367 staining was seen within RIP1-Tag5 tumors $(F)$, which are not infiltrated. Open arrows in $F$ point toward a RIP1-Tag5 tumor and indicate where the capsule meets the surrounding exocrine tissue. A MAdCAM-1-positive vessel is located at the periphery of, but not within, this representative tumor. $G-L$ : In contrast to MECA 79 and MECA 367, anti-PECAM-1 $(G-I)$ and anti-ICAM-1 $(J-L)$ staining of blood vessel endothelium did not vary among normal C3H islets, infiltrated RIP1-Tag5 islets, and tumors. (Anti-ICAM-1 stains infiltrating T lymphocytes [39] as well as blood vessel endothelium, contributing to the staining in the area of infiltration shown in $K$.) $M-O$ : Anti-VCAM-1 stained vessels in exocrine tissue and at the periphery of, but never within, $\mathrm{C} 3 \mathrm{H}$ islets $(M)$. In contrast, vessels within RIP1-Tag5 islets were VCAM-1-positive, again only in areas of infiltration ( $N$ ). RIP1-Tag5 tumors also contained abundant VCAM-1-positive vessels $(O)$. In all experiments, $10-\mu \mathrm{m}$ sections of pancreata were stained with the indicated antibody, and their binding was visualized with immuno-horseradish peroxidase, followed by counterstaining with hematoxylin. Infiltrating lymphocytes stain intensely with hematoxylin and appear dark blue within the islet shown in $B, E, H, K$, and $N$. Arrowheads point toward the islet and indicate the islet-exocrine tissue boundary in $A, B, D, E, G, H, J, K$, and $M$. The ages of mice were as follows: C3H mice, $20 \mathrm{wk}$; RIP1-Tag5 mice shown in $B$, $C, E, F, K, L, N$, and $O, 22 \mathrm{wk}$; RIP1-Tag5 mice shown in $H$ and $I, 17 \mathrm{wk}$. Because of the size of hyperplastic islets and tumors, only a representative section of the tissue is shown. $\times 200$. 

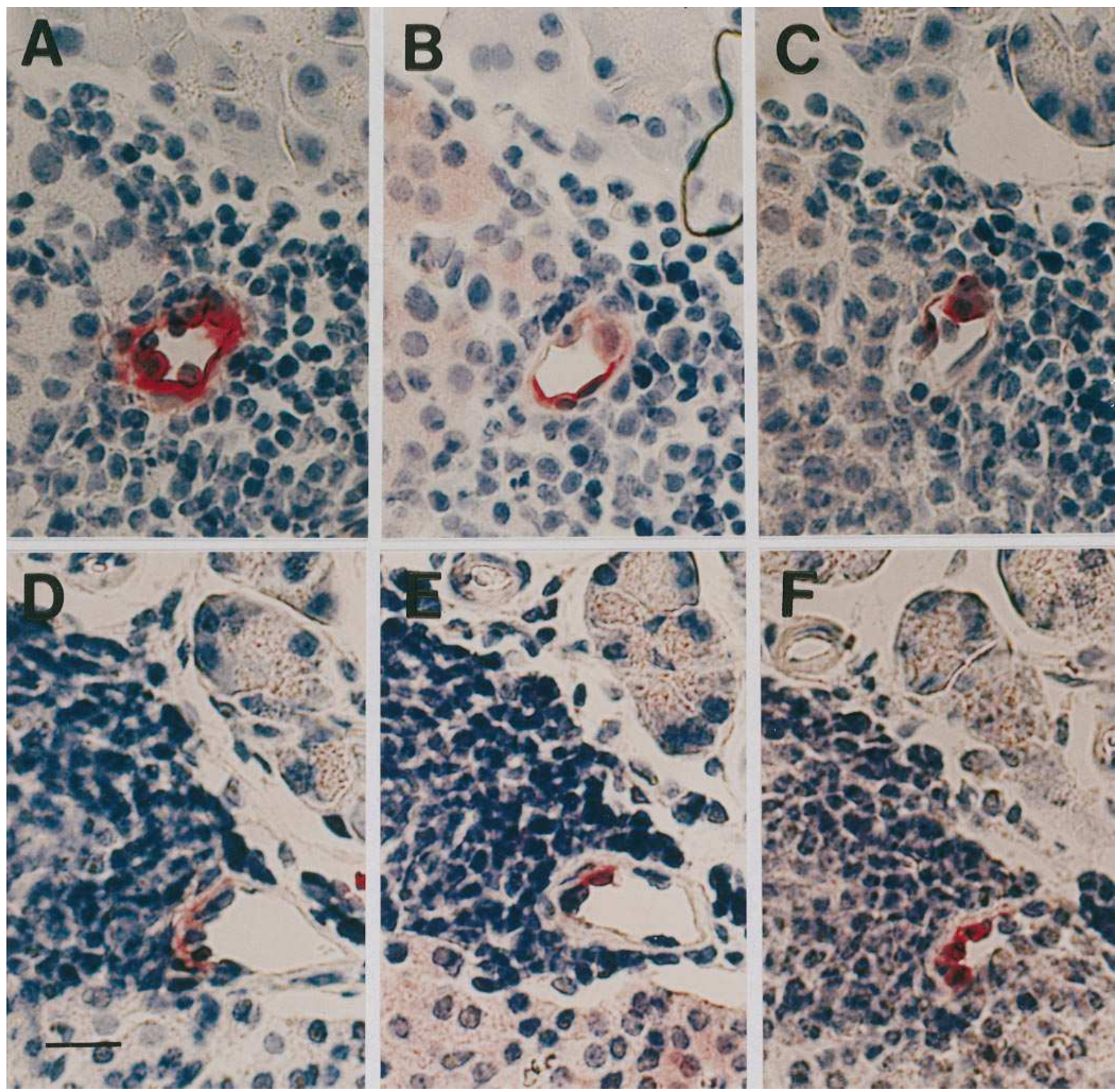

Figure 2. Expression of L-selectin ligands and GlyCAM-1 on HEV-like islet vessels in areas of infiltration. In RIP1-Tag5 pancreas sections, small mononuclear cells are seen adhering to walls of HEV-like vessels (see especially $A$ ), suggesting a high level of lymphocyte recruitment. Expression of L-selectin ligands and, specifically, GlyCAM-1 was induced on these vessels. It is especially clear in $C$ that single endothelial cells which express GlyCAM-1 are strikingly plump, while neighboring, GlyCAM-1-negative cells are not. Serial sections of paraffin-embedded pancreas from two 19-wk-old RIP1-Tag5 mice were reacted with: $A$ and $D$, MECA $79 ; B$ and $E$, LEC-IgG; $C$ and $F$, anti-GlyCAM-1, developed with immuno-alkaline phosphatase and counterstained with hematoxylin. $\times 400$. Bar, $20 \mu \mathrm{m}$.

lyzed by immunoprecipitation. Material which bound nonspecifically to beads was first removed by incubation of $\mathrm{CM}$ with $25 \mu \mathrm{l}$ each of protein A-Sepharose and anti-rat Ig-Sepharose (both from Zymed Laboratories, Inc., South San Francisco, CA) two times for $1 \mathrm{~h}$ at $4^{\circ} \mathrm{C}$ with gentle rocking. $\mathrm{mAb}$ or antisera and Sepharose beads were added to samples simultaneously as follows: $10 \mu \mathrm{g}$ MECA 79 or control rat IgM and $25 \mu \mathrm{l}$ anti-rat Ig-Sepharose, or $20 \mu \mathrm{l}$ preimmune or anti-GlyCAM-1 serum and $25 \mu \mathrm{l}$ protein A-Sepharose. After $2 \mathrm{~h}$ at $4^{\circ} \mathrm{C}$ with gentle rocking, supernatants were transferred to fresh tubes, beads were washed 5 times with wash buffer (PBS containing $0.2 \%$ Triton X-100), and bound protein was eluted in SDS-PAGE sample buffer (51) by boiling. For identification of MECA 79-reactive species as GlyCAM-1 (see Fig. 4, lanes 3, 9, and 15), CM precleared by incubation with anti-GlyCAM-1 serum and protein A-Sepharose beads was further incubated for $2 \mathrm{~h}$ at $4^{\circ} \mathrm{C}$ with $10 \mu \mathrm{g}$ MECA 79 and $25 \mathrm{ml}$ anti-rat Ig-Sepharose, and bound protein was eluted in SDSPAGE sample buffer by boiling. LEC-IgG beads were prepared by covalently cross-linking LEC-IgG bound to protein A-Sepharose via its IgG segment using dimethyl pimelimidate (52) at $10 \mathrm{mg} / \mathrm{ml}$ beads. To isolate L-selectin ligands, nonspecific protein was removed as above from $\mathrm{CM}$ corresponding to $1 \mathrm{mg}$ lysate protein. Then, the sample was incubated for $2 \mathrm{~h}$ with $2.5 \mu \mathrm{l}$ LEC-IgG beads, and, after wash- 
ing beads as described above, protein was eluted from beads by the addition of $200 \mu \mathrm{l}$ wash buffer containing $10 \mathrm{mM}$ EDTA. Eluted protein was precipitated with acetone, resuspended in SDS-PAGE sample buffer, and boiled. Protein was resolved on 10\% acrylamide-SDS gels under reducing conditions (51), and gels were processed with Fluorohance (Research Products International Corp., Mount Prospect, IL) to enhance signals before exposure to film at $-80^{\circ} \mathrm{C}$.

\section{Results}

In nontolerant RIP1-Tag5 mice, vascular addressin expression is induced on islet but not on tumor vessel endothelium. The character of lymphocyte infiltration of pancreatic islets in the nontolerant RIP1-Tag5 mouse line is similar to that reported for the RIP1-Tag3 line $(42,44)$. The RIP1-Tag5 line was produced in the $\mathrm{C} 3 \mathrm{Heb} / \mathrm{FeJ}(\mathrm{C} 3 \mathrm{H})$ background, which is a high responder for humoral autoimmunity. Infiltrates are detected as early as $14-15$ wk of age, $3-5$ wk after $\beta$ cells first begin to express Tag (Jolicoeur, C., K. Smith, and D. Hanahan, unpublished observations). Infiltration is seen in up to $60 \%$ of islets and can be accompanied by areas of apparent $\beta$ cell destruction. Immunohistochemical staining of pancreas sections from RIP1-Tag5 mice showed that the infiltrates consisted of CD8 ${ }^{+}$ and $\mathrm{CD}^{+} \mathrm{T}$ cells, B cells, and macrophages (not shown). Islets in RIP1-Tag2 mice, which are tolerant to Tag, do not become infiltrated. In both tolerant and nontolerant mice, Tag oncoprotein expression results in proliferative hyperplasia, induction of angiogenesis, and progression to solid tumors (41, 42, 53). Therefore, in addition to $\mathrm{C} 3 \mathrm{H}$ mice, RIP1-Tag2 mice provided a useful control for this study since they are distinguished from RIP1-Tag5 mice by immune tolerance of Tag.

Small, mononuclear cells were often seen adhering to the walls of HEV-like vessels in areas of infiltration in RIP1-Tag5 islets (for example, see Fig. 2), indicating ongoing lymphocyte recruitment. To determine if expression of endothelial adhesion molecules could be correlated with the mononuclear infiltration of islets, immunohistochemistry was performed on nontransgenic $\mathrm{C} 3 \mathrm{H}$ and RIP1-Tag5 mouse pancreas sections. These experiments used the MECA 79 and MECA $367 \mathrm{mAbs}$, to detect PNAd and MAdCAM-1, respectively, and PECAM-1, ICAM-1, and VCAM-1 mAbs (Fig. 1).

PNAd expression was not observed in nontransgenic $\mathrm{C} 3 \mathrm{H}$ (Fig. $1 A$ ) or tolerant RIP1-Tag2 (not shown) pancreatic islets or exocrine tissue. MAdCAM-1 was expressed on some vessels in exocrine tissue and at the periphery of many islets from nontransgenic $\mathrm{C} 3 \mathrm{H}$ mice, but never within these islets (Fig. 1 $D)$. However, PNAd and MAdCAM-1 were both expressed at high levels on HEV-like endothelium within infiltrated RIP1Tag5 islets (Fig. 1, $B$ and $E$ ). Areas of infiltration were identified by visual inspection and detection of $\mathrm{T}$ and $\mathrm{B}$ lymphocytes in serial sections with CD4, CD8, and B220 mAb (not shown). PNAd expression, and intraislet induction of MAdCAM-1 expression, was completely localized to infiltrated areas. In mesenteric lymph nodes, individual HEV cells typically express both PNAd and MAdCAM-1 (9). As shown in Fig. 1, $B$ and $E$, staining of serial sections revealed coincident staining of HEVlike vessels by MECA 79 and MECA 367. Strikingly, no expression of PNAd or MAdCAM-1 was ever seen within RIP1Tag5 tumors (Fig. 1, $C$ and $F$ ), although vessels expressing MAdCAM-1 were sometimes seen at the periphery of tumors (Fig. $1 F$ ).
In marked contrast to PNAd and MAdCAM-1, PECAM-1 was expressed on virtually all vessels in both exocrine pancreas and within islets, and levels of expression were indistinguishable among control $\mathrm{C} 3 \mathrm{H}$ islets, infiltrated RIP1-Tag5 islets, and RIP1-Tag5 tumors (Fig. 1, $G-I$ ). ICAM-1 was expressed on many vessels within exocrine pancreas and islets. As seen with PECAM-1, the pattern of expression of ICAM-1 appeared to be similar among vessels within $\mathrm{C} 3 \mathrm{H}$ islets, infiltrated RIP1-Tag5 islets, and RIP1-Tag5 tumors (Fig. 1, J-L). Although interpretation of expression in infiltrated areas of RIP1-Tag5 islets was complicated by ICAM-1 expression on some infiltrating lymphocytes (39), this adhesion molecule was clearly expressed on islet vessels outside areas of infiltration. VCAM-1 was expressed on some vessels in the exocrine pancreas, but less frequently than ICAM-1. Similar to MAdCAM-1, VCAM-1 expression was sometimes seen on vessels at the periphery, but was not observed within $\mathrm{C} 3 \mathrm{H}$ islets (Fig. $1 M$ ). VCAM-1 expression was induced on endothelium within areas of infiltration in RIP1-Tag5 islets (Fig. $1 \mathrm{~N}$ ), but was not seen within noninfiltrated RIP-Tag5 islets (not shown). In striking contrast to MAdCAM-1 and PNAd, VCAM-1 was also expressed on endothelium in RIP1-Tag5 tumors (Fig. $1 O$ ). To further characterize VCAM-1 expression on islet and tumor endothelium, we examined islets and tumors from tolerant RIP1-Tag2 mice, which do not show inflammation of islets. VCAM-1 was expressed on vessels within both islets and tumors from a 14-wk-old RIP-Tag2 mouse (not shown). Thus, expression of VCAM-1 did not correlate with infiltration.

The results of this immunohistochemical analysis are summarized in Table II and indicate that PNAd, MAdCAM-1, and VCAM-1 expression was not detected on endothelium within normal islets of $\mathrm{C} 3 \mathrm{H}$ mice. Among the endothelial adhesion molecules studied, only the vascular addressins and VCAM-1 were induced in areas of inflammation resulting from nontolerance to Tag. However, in tumors, VCAM-1 was present, whereas PNAd and MAdCAM-1 expression was never seen. Therefore, only vascular addressin expression correlated with infiltration.

L-Selectin ligands are expressed on the same islet vessels as PNAd and MAdCAM-1. We used a soluble, recombinant Ig chimera of L-selectin, LEC-IgG, as an immunohistochemical probe to directly demonstrate that the observed expression of PNAd on infiltrated islet endothelium (as detected with MECA

Table II. Summary of Endothelial Expression of Adhesion Molecules in Mouse Islets

\begin{tabular}{lccc}
\hline $\begin{array}{c}\text { Endothelial } \\
\text { adhesion molecule }\end{array}$ & C3H islets & $\begin{array}{c}\text { RT5 infiltrated } \\
\text { islets }\end{array}$ & RT5 tumors \\
\hline L-Selectin ligands & - & + & - \\
MAdCAM-1 & + & + & - \\
PECAM-1 & + & + & + \\
ICAM-1 & + & + & + \\
VCAM-1 & - & + & + \\
\hline
\end{tabular}

+ refers to expression of the indicated adhesion molecule on blood vessel endothelium within islets or tumors as detected by immunohistochemistry; - indicates no such expression was detected; RT5 indicates nontolerant RIP1-Tag5 mice between the ages of 16 and 24 wk. 20-wk-old $\mathrm{C} 3 \mathrm{H}$ mice served as normal, nontransgenic controls. 
79) corresponded to the presence of ligands for L-selectin (Fig. 2). LEC-IgG consists of the entire extracellular domain of mouse L-selectin joined to the hinge region and two constant domains ( $\mathrm{CH} 2$ and $\mathrm{CH} 3$ ) of human $\mathrm{IgG}_{1}$ (46). LEC-IgG has ligand specificity identical to that of L-selectin, based on a wide variety of assays (46), whereas MECA 79 binds to a portion of the carbohydrate structure recognized by L-selectin (23).

Similar to MECA 79, LEC-IgG stained islet vessels, but only in areas of infiltration in RIP1-Tag5 pancreas sections. In addition, LEC-IgG failed to stain vessels in RIP1-Tag2 islets or tumors from either tolerant or nontolerant mice (not shown). To compare PNAd with L-selectin ligand expression, serial sections were stained with MECA 79 (Fig. 2, $A$ and $D$ ) and LEC-IgG (Fig. 2, $B$ and $E$ ), respectively. Examination of the same islet vessel in three or more serial sections revealed that in $61 \%(11 / 18)$ of infiltrated islets, MECA 79-positive vessels were also stained with LEC-IgG (not shown). The lack of complete correspondence between MECA 79 and LEC-IgG staining of vessels in infiltrated islets may be attributed to L-selectin's recognition of a subset of MECA 79-binding glycoproteins $(16,23)$. Lower sensitivity of staining with LECIgG as compared with MECA 79 may also contribute to the difference. Like binding of L-selectin to its lymph node HEV ligands, staining with LEC-IgG was dependent on the presence of divalent cations and was significantly reduced by treatment of sections with sialidase (not shown). Weak background staining was restricted to noninfiltrated islet tissue and was judged to be nonspecific because it was not dependent on the presence of divalent cations (not shown). Therefore, expression of L-selectin ligands was induced on RIP1-Tag5 islet endothelium specifically in areas of infiltration.

We next asked which of the characterized lymph node HEV ligands for L-selectin, GlyCAM-1 or CD34, was expressed on endothelium in infiltrated islets. An anti-GlyCAM-1 antibody (21) was used to assess GlyCAM-1 expression in pancreas sections (Fig. 2, $C$ and $F$ ). The analysis revealed that GlyCAM-1 was induced on islet endothelium exclusively in areas of infiltration and was not detected on any vessels in normal islets, in tumors, or in exocrine tissue. Vessels in both exocrine and islet tissue of RIP1-Tag2 and RIP1-Tag5 pancreas sections also expressed CD34 (not shown), as detected by an affinity-purified polyclonal antibody against mouse CD34 (22). This result is consistent with widespread expression of this protein on endothelium $(25,26)$. As shown in Fig. 1, expression of MAdCAM-1 was also upregulated on vessels in infiltrated islets. Thus, three molecules that can potentially function as L-selectin ligands were expressed at this site: GlyCAM-1, CD34, and MAdCAM-1; of these, GlyCAM-1 and MAdCAM-1 were upregulated.

Expression of GlyCAM-1 was then investigated at the biochemical level. Based on immunohistochemistry, PNAd and L-selectin ligand expression appeared to be maximal in pancreata of 17-20-wk-old RIP1-Tag5 mice. Therefore, islets and tumors were isolated from pancreata of 18.5-wk-old RIP1Tag5 mice by collagenase digestion. Islets and tumors from 10 14-wk-old RIP1-Tag2 mice were analyzed in parallel. The steady state levels of GlyCAM-1 mRNA in isolated islets and tumors were measured by Northern analysis (Fig. 3). Consistent with immunohistochemical staining, RIP1-Tag5 islets (Fig. 3, lane 2) had easily detectable levels of GlyCAM-1 mRNA. In contrast, GlyCAM-1 mRNA was not detected in islets from
RIP1-Tag2 animals (Fig. 3, lane 4), even after prolonged autoradiography (not shown). Pancreatic lymph nodes expressed high levels of GlyCAM-1 (not shown). Thus, the absence of GlyCAM-1 RNA from RIP1-Tag2 islets confirmed that the islet preparations were not contaminated with pancreatic lymph nodes. Tumors from RIP1-Tag5 animals (Fig. 3, lane 3) had very little, if any, GlyCAM-1 mRNA, and no expression could be detected in RIP1-Tag2 tumors (Fig. 3, lane 5). Measurement of steady state levels of $\beta$-actin mRNA in the same experiment demonstrated that an equal amount of each type of RNA was analyzed, with the exception of RIP1-Tag5 tumor RNA, which contained at least twice as much RNA (not shown). This RNA analysis validated the immunohistochemical detection of GlyCAM-1 in RIP1-Tag5 islets shown in Fig. 2, $C$ and $F$. Consistent with the higher frequency of HEV seen in lymph nodes, the level of GlyCAM-1 mRNA was much higher in lymph nodes than in RIP1-Tag5 islets (Fig. 3, lanes 1 and 2).

GlyCAM-1 expressed on infiltrated islet endothelium is an L-selectin ligand. To determine if GlyCAM-1 expressed in infiltrated islets was an L-selectin ligand, isolated islets and tumors were metabolically labeled with $\left[{ }^{35} \mathrm{~S}\right]$ sulfate, and GlyCAM-1 protein was analyzed. Sulfate was chosen as a radiolabel since recognition of HEV ligands by both MECA 79 and L-selectin depends on sulfation $(20,23)$. GlyCAM- 1 is detected at 5-10-fold higher levels in CM from lymph node organ cultures than in lysates (20); therefore, CM from islet and tumor cultures was analyzed.

As shown in Fig. 4, MECA 79 immunoprecipitated a single $\sim 50-\mathrm{kD}$ sulfated species from CM of RIP1-Tag5 islets (lane 8 ), which comigrated with GlyCAM-1 that was immunoprecipitated by MECA 79 from CM of lymph nodes (lane 2). The MECA 79-reactive molecule from RIP1-Tag5 islets was GlyCAM-1, because preclearing the sample with anti-GlyCAM-1 eliminated the 50-kD species from a subsequent MECA 79 immunoprecipitation (Fig. 4, lane 9). Direct immunoprecipitation with anti-GlyCAM-1 demonstrated that GlyCAM-1 from RIP1-Tag5 islet CM was indeed sulfated and migrated at 50 kD (Fig. 4, lane 11). LEC-IgG also recognized GlyCAM-1 in

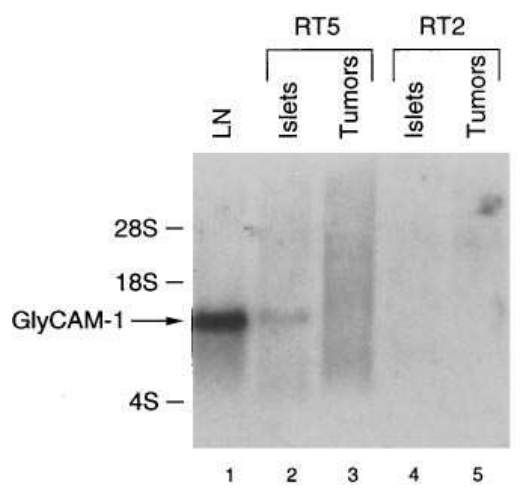

Figure 3. GlyCAM-1 mRNA is expressed in infiltrated hyperplastic islets. Steady state levels of GlyCAM-1 mRNA in tissues were measured by Northern analysis. A radiolabeled mouse GlyCAM1 cDNA was used to probe total cellular RNA isolated from: lane 1 , mesenteric lymph nodes; lane 2, RIP1-Tag5 (RT5) is-

lets; lane 3, RT5 tumors; lane 4, RIP1-Tag2 (RT2) islets; lane 5, RT2 tumors. The RT5 and RT2 mice were 18.5 and 14 wk old, respectively. Migration of $28 \mathrm{~S}, 18 \mathrm{~S}$, and $4 \mathrm{~S}$ ribosomal RNAs is indicated. Visualization of RNA in the gel with ethidium bromide and rehybridization of this filter with a radiolabeled human $\beta$-actin cDNA (not shown) demonstrated that equal amounts of intact RNA were loaded in each lane, except lane 3 had approximately twice as much RNA as the other lanes. 


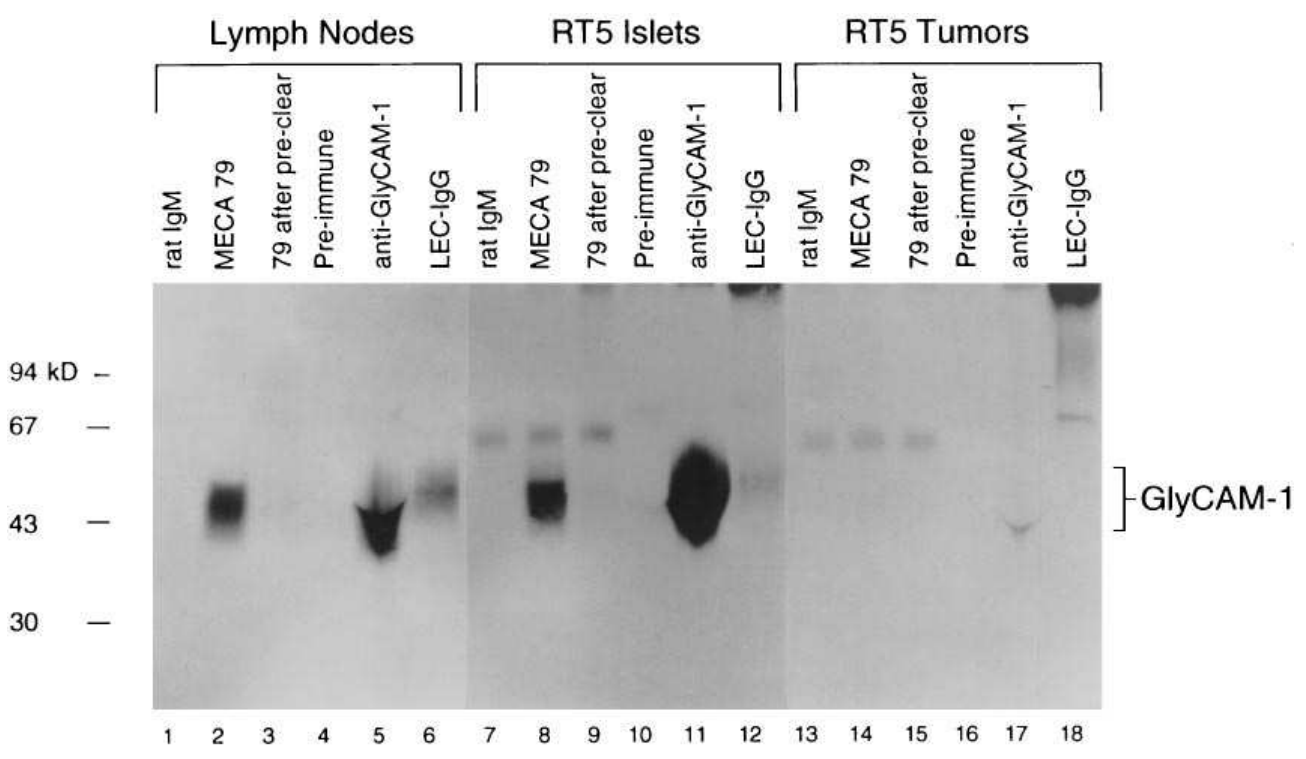

Figure 4. GlyCAM-1 from infiltrated islet cultures is a ligand for L-selectin. To identify GlyCAM-1 as MECA 79-reactive and an L-selectin ligand, immunoprecipitations were performed with the indicated reagents. The starting material was CM from peripheral and mesenteric lymph nodes (lanes 1-6), RIP1-Tag5 (RT5) islets (lanes 7-12) or RT5 tumors (lanes 13-18) metabolically labeled with $\left[{ }^{35} \mathrm{~S}\right]$ sodium sulfate. The migration of lymph node GlyCAM-1 is indicated at right. rat IgM refers to an isotype-matched control antibody for MECA 79. For lanes 3, 9 , and 15 (79 after pre-clear), GlyCAM-1 protein was precleared from CM by incubation with anti-GlyCAM-1 bound to

protein A-Sepharose, then a MECA 79 immunoprecipitation was performed. Lanes 1-6 were exposed to film for $4 \mathrm{~h}$ while lanes 7-18 were exposed for $8 \mathrm{~d}$. Volume of CM corresponded to $1 \mathrm{mg}$ detergent lysate protein/lane. The distortion of the GlyCAM-1 band in lanes 5,11, and 17 results from comigration with unlabeled heavy chain of the rabbit anti-GlyCAM-1 serum. This distortion is not seen in MECA 79 or control rat IgM monoclonal antibody lanes because less antibody-associated protein was added to these precipitations. LEC-IgG was covalently bound to protein A-Sepharose and therefore not present in the sample loaded on the SDS gel. The 60-kD species seen in lanes 7-9 and 13-15 was precipitated by both control rat IgM and MECA 79 and was therefore judged to be nonspecific. Although the 70- and 90-kD species precipitated from RT5 tumor CM by LEC-IgG (lane 18) were not defined, the 90-kD material was not recognized by the anti-mouse CD34 antibody (not shown).

RIP1-Tag5 CM (Fig. 4, lane 12); preclearing with anti-GlyCAM-1 eliminated this $50-\mathrm{kD}$ species from a subsequent LECIgG precipitation (not shown). Binding of LEC-IgG to secreted islet GlyCAM-1 was sensitive to the addition of EDTA, as expected for L-selectin's calcium-dependent lectin activity (not shown). As is the case in lymph nodes, only a fraction of the total sulfated GlyCAM-1 in RIP1-Tag5 islet CM was recognized by MECA 79 or LEC-IgG (Fig. 4, compare lanes 8 , 11, and 12). Although virtually no MECA 79 reactivity was detected in RIP1-Tag5 tumor CM, a very low level of sulfated GlyCAM-1 was present (Fig. 4, lane 17). This signal may correspond to the MECA 79 reactivity seen at the periphery of nascent tumors by immunohistochemistry (not shown). GlyCAM-1 was not detected in CM from RIP1-Tag2 islets or tumors, consistent with the immunohistochemical analyses (not shown). Thus, the biochemical analysis directly demonstrated that GlyCAM-1 secreted from RIP1-Tag5 islets was a ligand for L-selectin.

Of interest, examination of serial sections stained with LEC-IgG and anti-GlyCAM-1 revealed that LEC-IgG stained some vessels in infiltrated RIP1-Tag5 islets that did not express GlyCAM-1 (16\%, 2/12), suggesting the possible presence of other ligands for L-selectin. CD34 and MAdCAM-1 are candidates for these additional ligands, based on their colocalization with LEC-IgG staining (not shown, and Figs. 1 and 2). However, efforts at biochemical identification were not successful. We failed to detect either of these molecules in detergent lysates of $\left[{ }^{35}\right.$ S $]$ sulfate-labeled RIP1-Tag5 islets by immunoprecipitation with MECA 79 or LEC-IgG.

\section{Discussion}

Delayed onset of Tag expression in the $\beta$ cells of RIP1-Tag5 mice results in a nonself response against cells expressing this protein. One consequence of the nonself recognition of Tag is lymphocytic infiltration of islets. Simultaneously, Tag expression initiates multistage tumorigenesis, the progress of which depends on the ability of tumor cells to avoid immune-mediated destruction of Tag-expressing $\beta$ cells. We have examined the blood vessels in islets in these mice for the expression of L-selectin ligands, MAdCAM-1, PECAM-1, ICAM-1, and VCAM-1. The results suggest that differential modulation of expression of vascular addressins may be important both for islet infiltration and tumor progression.

Selective induction of L-selectin ligands and MAdCAM-1 in infiltrated hyperplastic islets. Expression of L-selectin ligands and MAdCAM-1, as defined by LEC-IgG and MECA 367, respectively, was induced on endothelium in RIP1-Tag5 islets exclusively in areas of infiltration. No induction of L-selectin ligand or MAdCAM-1 expression was observed in the islets of nontransgenic $\mathrm{C} 3 \mathrm{H}$ or tolerant RIP1-Tag2 mice, which do not become infiltrated. Although VCAM-1 was induced in areas of infiltration of nontolerant RIP1-Tag5 islets, this adhesion molecule was also expressed on vessels in islets and tumors of tolerant RIP1-Tag2 mice, and in RIP1-Tag5 tumors, which were not infiltrated. Thus, lymphocyte infiltration of islets was clearly correlated with intraislet expression of L-selectin ligands and MAdCAM-1 and not with expression of PECAM-1, ICAM-1, or VCAM-1. These observations are similar to the situation in NOD mice $(11,34)$. Thus, as in NOD mice, the induction of L-selectin ligand and MAdCAM-1 expression may play an important role in recruitment of lymphocytes to islets during the Tag-induced autoimmune response. Based on what is known about the role of these ligands' lymphocyte receptors in lymphocyte extravasation, we expect that induction of L-selectin ligand and MAdCAM-1 expression precedes lymphocyte entry to islets. However, when looking at very early stages of infiltration, Hänninen et al. (11) were not able to separate the 
onset of lymphocyte entry from the induction of PNAd expression, suggesting that these two events are very closely linked. An answer to this question awaits development of an appropriate in vitro model in which these molecules can be manipulated.

We identified GlyCAM-1 as one of the L-selectin ligands that was induced on infiltrated islet endothelium. The expression of GlyCAM-1 in a glycoform recognized by L-selectin has thus far been observed only at sites of lymphocyte recruitment: on HEV of lymph nodes (21), and on HEV-like vessels in infiltrated islets in RIP1-Tag5 mice (this study), RIP-TNFo transgenic mice (Vassalli, P., personal communication), and NOD mice (25). Thus, this protein likely plays a role in L-selectindependent recruitment of lymphocytes to inflamed islets as well as lymph nodes. While GlyCAM-1 on the endothelial cell surface should permit L-selectin-dependent adhesion of lymphocytes, this glycoprotein is largely secreted (54). The secreted form of GlyCAM-1 may impart a signal via L-selectin which activates lymphocyte integrins and permits firm adhesion during lymphocyte extravasation (Hwang, S. T., M. S. Singer, T. Yednock, K. B. Bacon, P. A. Giblin, S. I. Simon, and S. D. Rosen, manuscript in preparation).

L-selectin ligand(s) in addition to GlyCAM-1 were also induced on infiltrated islet endothelium, since LEC-IgG stained infiltrated islet endothelium at some sites where GlyCAM-1 did not appear to be expressed. Although CD34 and MAdCAM-1 were likely candidates for these additional inflammatory ligand(s), we were unable to demonstrate by immunoprecipitation or immunoblotting that either protein carried the MECA 79 epitope or served as a functional ligand for L-selectin. These negative findings probably reflect very low abundance. GlyCAM-1 and CD34 were difficult to detect in RIP1Tag5 islet lysates, and, by analogy with GlyCAM-1 in CM, only a subset of these molecules was expected to carry the MECA 79 epitope or interact with L-selectin. Sulfated MAdCAM-1 was detected at 25-50-fold lower levels than GlyCAM-1 in mesenteric lymph node lysates (not shown), and MAdCAM-1 is expected to be present at correspondingly low levels in islets. Development of more sensitive techniques should permit unambiguous assessment of CD34 and MAdCAM-1 as L-selectin ligands in infiltrated islets. Moreover, specific reagents are not yet available for immunohistochemical localization of Sgp200, found in lymph nodes (23), or another, heparin-based ligand for L-selectin which has been reported in cultured endothelial cells (55), though these molecules warrant analysis. Of interest, CD34 was sulfated in both RIP1-Tag5 and RIP1-Tag2 islets and in tumors from both nontolerant and tolerant RIP-Tag animals. Thus, sulfation alone was not predictive of L-selectin ligand function or MECA 79 reactivity.

How is expression of L-selectin ligands, MAdCAM-1 and VCAM-1, induced at this inflammatory site? Neither oncogene expression nor its consequences ( $\beta$ cell hyperproliferation [41] and neovascularization [53]) are sufficient to induce expression of these adhesion molecules, because induction of L-selectin ligand and MAdCAM-1 expression within islets was not observed in tolerant mice. It is possible that the constitutive level of MAdCAM-1 expressed on both periislet and exocrine endothelium in both RIP1-Tag2 and RIP1-Tag5 mice contributes to routine surveillance by $\alpha_{4} \beta_{7}$-bearing $T$ cells. When Tag-specific $\mathrm{T}$ cells encounter Tag-expressing islet $\beta$ cells, the consequent activation could involve the release of soluble signals which upregulate expression of L-selectin ligands, MAdCAM-1 and VCAM-1. Initial non-antigen-specific recruitment of lymphocytes, and inflammation, would follow. The low frequency of L-selectin ligand- and MAdCAM-1-expressing vessels suggests the possibility that other adhesion molecules could mediate later stages of the inflammation. Soluble factors released by activated macrophages or lymphocytes have been implicated in regulation of PNAd and MAdCAM-1 expression on HEV in lymph nodes (56-58) and may also be involved in islets. Similarly, VCAM-1 expression on endothelial cells is induced by several inflammatory signals (for review see reference 38).

Localized induction of GlyCAM-1, other L-selectin ligands, and MAdCAM-1 on islet vessels involves regulation at two levels. First, expression of MAdCAM-1 and GlyCAM-1 was upregulated at the protein level, and, as demonstrated for GlyCAM-1, at the RNA level. In contrast, CD34 is expressed constitutively on endothelium $(25,26)$. Second, for appropriate carrier molecules to display carbohydrate structure(s) recognized by L-selectin, specific glycosyl- and sulfotransferases involved in synthesis must also be expressed. The glycosyl- and sulfotransferases associated with ligand synthesis in lymph node HEV have not been defined, and those used in islets could differ from those in lymph nodes.

A failure of tumor immunity. In contrast to endothelium in infiltrated RIP1-Tag5 islets, the endothelium in tumors, which were not infiltrated, did not express detectable levels of PNAd and MAdCAM-1. However, three other adhesion molecules implicated in lymphocyte extravasation, PECAM-1, ICAM-1, and VCAM-1, were each expressed both in islets and tumors. It is particularly notable that VCAM-1, whose upregulation is a hallmark of "activated" endothelium seen in inflammatory responses, is expressed at increased levels on endothelium in both infiltrated islets and noninfiltrated tumors. Thus, it is the striking lack of vascular addressin expression that correlates with progression to solid tumors. This finding suggests the possibility that interference with addressin expression might be manifested during tumorigenesis such that tumors can evade or minimize immune surveillance and consequent attack.

How might tumors in nontolerant mice avoid induction of vascular addressin expression and lymphocyte infiltration despite expressing high levels of Tag? One possibility is that the tumor cells (but not preneoplastic islet cells) release paracrine inhibitors that act on the tumor vessel endothelium, or on the infrequent lymphocytes extravasating during normal immune surveillance, to prevent induction of HEV-like vessels in the tumor. Another possibility is that the tumor vessels are different from normal endothelium and somehow are incapable of developing into HEV. A model that explains how tumors downmodulate addressin expression must account for the localization of this effect within tumors, since hyperplastic islets in close proximity to tumors are frequently infiltrated and exhibit induction of vascular addressins.

Currently we favor a paracrine suppressor model, since increasing the abundance of Tag-reactive T cells through the use of anti-Tag $\mathrm{T}$ cell receptor transgenes results in infiltration of both islets and tumors in RIP1-Tag2 mice (59), which are tolerant to Tag and normally devoid of inflammation. This infiltration is concomitant with induction of HEV-like vessels and expression of PNAd and MAdCAM-1 (Hirose, R., P. M. Hartl, and D. Hanahan, unpublished observations), suggesting that abundant anti-Tag $\mathrm{T}$ lymphocytes can overwhelm whatever mechanism suppresses addressin induction in tumors. In a 
recent study, VCAM-1 expression was suppressed on small blood vessels in a solid tumor within lungs, apparently by soluble factors secreted by the tumor (60). Although differing with respect to VCAM-1 regulation, our results also suggest that a tumor-associated activity could modulate vascular addressin expression.

The work presented here suggests that tumor evasion of immune surveillance and a chronic inflammatory response with hallmarks of organ-specific autoimmunity both rely in part on modulation of expression of L-selectin ligands and MAdCAM-1. Thus, the ability to control expression of these molecules might be exploited in generalized approaches aimed at either inducing tumor immunity by their upregulation or curtailing inflammation associated with diseases such as type I diabetes by rendering the target tissue invisible, much as the tumors in these transgenic mice.

\section{Acknowledgments}

We thank M. S. Singer for essential help with techniques; K. Smith, R. Hirose, and members of the Rosen lab for advice and critical reading of the manuscript; P. Vassalli for sharing data in advance of publication; E. C. Butcher, M. S. Singer, L. Lasky, S. Watson, S. Baumhueter, D. Dowbenko, and A. Weiss for providing reagents; R. Nagal for animal husbandry; and F. Loeffler for analyzing transgenic mice.

This research was supported by grants from the National Institutes of Health to D. Hanahan and from the National Institutes of Health (GM-23547) and Genentech, Inc. to S. D. Rosen. S. V. Onrust was the recipient of a Postdoctoral Fellowship from the American Cancer Society, and P. M. Hartl was a Fellow of the Cancer Research Institute. We acknowledge the support of the UCSF Transgenic Mouse Facility by the Markey Charitable Trust.

\section{References}

1. Gowans, J. L., and E. J. Knight. 1964. The route of recirculation of lymphocytes in the rat. Proc. R. Soc. Lond. Ser. B. Biol. Sci. 159:257-282.

2. Freemont, A. 1987. Molecules controlling lymphocyte-endothelial interactions in lymph nodes are produced in vessels of inflamed synovium. Ann. Rheum. Dis. 46:924-928.

3. Higuchi, Y., P. Herrera, P. Muniesa, J. Huarte, D. Belin, P. Ohashi, P. Aichele, L. Orci, J. D. Vassalli, and P. Vassalli. 1992. Expression of a tumor necrosis factor alpha transgene in murine pancreatic beta cells results in severe and permanent insulitis without evolution towards diabetes. J. Exp. Med. 176: 1719-1731.

4. Bargatze, R. F., S. Kurk, E. C. Butcher, and M. A. Jutila. 1994. Neutrophils roll on adherent neutrophils bound to cytokine-induced endothelial cells via L-selectin on the rolling cells. J. Exp. Med. 180:1785-1792.

5. Berg, E. L., L. M. McEvoy, C. Berlin, R. F. Bargatze, and E. C. Butcher. 1993. L-selectin-mediated lymphocyte rolling on MAdCAM-1. Nature (Lond.). 366:695-698.

6. Berlin, C., E. L. Berg, M. J. Briskin, D. P. Andrew, P. J. Kilshaw, B. Holzmann, I. L. Weissman, A. Hamann, and E. C. Butcher. 1993. $\alpha 4 \beta 7$ integrin mediates lymphocyte binding to the mucosal vascular addressin MAdCAM-1. Cell. 74:185-195.

7. Berlin, C., R. F. Bargatze, J. T. Campbell, U. H. von Adrian, M. C. Szabo, S. R. Hasslen, R. D. Nelson, E. L. Berg, S. L. Erlandsen, and E. C. Butcher. 1995. Alpha4 integrins mediate lymphocyte attachment and rolling under physiologic flow. Cell. 80:413-422.

8. Streeter, P. R., E. L. Berg, B. T. N. Rouse, R. F. Bargatze, and E. C. Butcher. 1988. A tissue-specific endothelial cell molecule involved in lymphocyte homing. Nature (Lond.). 331:41-46.

9. Streeter, P. R., B. T. N. Rouse, and E. C. Butcher. 1988. Immunohistologic and functional characterization of a vascular addressin involved in lymphocyte homing into peripheral lymph nodes. J. Cell Biol. 107:1853-1862.

10. Briskin, M. J., L. M. McEvoy, and E. C. Butcher. 1993. MAdCAM-1 has homology to immunoglobulin and mucin-like adhesion receptors and to IgA1. Nature (Lond.). 363:461-464.

11. Hänninen, A., C. Taylor, P. R. Streeter, L. S. Stark, J. M. Sarte, J. A. Shizuru, O. Simell, and S. A. Michie. 1993. Vascular addressins are induced on islet vessels during insulitis in nonobese diabetic mice and are involved in lymphoid binding to islet endothelium. J. Clin. Invest. 92:2509-2515.
12. Bevilacqua, M., E. Butcher, B. Furie, B. Furie, M. Gallatin, M. Gimbrone, J. Harlan, K. Kishimoto, L. Lasky, R. McEver, et al. 1991. Selectins: a family of adhesion receptors. Cell. 67:233.

13. Rosen, S. D., and C. R. Bertozzi. 1994. The selectins and their ligands. Curr. Opin. Cell Biol. 6:663-673.

14. Rosen, S. D., M. S. Singer, T. A. Yednock, and L. M. Stoolman. 1985. Involvement of sialic acid on endothelial cells in organ-specific lymphocyte recirculation. Science (Wash. DC). 228:1005-1007.

15. Imai, Y., M. S. Singer, C. Fennie, L. A. Lasky, and S. D. Rosen. 1991. Identification of a carbohydrate-based endothelial ligand for a lymphocyte homing receptor. J. Cell Biol. 113:1213-1221.

16. Berg, E. L., M. K. Robinson, R. A. Warnock, and E. C. Butcher. 1991 The human peripheral lymph node vascular addressin is a ligand for LECAM-1, the peripheral lymph node homing receptor. J. Cell Biol. 114:343349.

17. Hemmerich, S., H. Leffler, and S. D. Rosen. 1995. Structure of the $O$-glycans in GlyCAM-1, an endothelial-derived ligand for L-selectin. J. Biol. Chem. 270:12035-12047.

18. Hemmerich, S., and S. D. Rosen. 1994. 69-sulfated, sialyl Lewis $\times$ is a major capping group of GlyCAM-1. Biochemistry. 33:4830-4835.

19. Hemmerich, S., C. R. Bertozzi, H. Leffler, and S. D. Rosen. 1994. Identification of the sulfated monosaccharides of GlyCAM-1, an endothelial derived ligand for L-selectin. Biochemistry. 33:4820-4829.

20. Imai, Y., L. A. Lasky, and S. D. Rosen. 1993. Sulphation requirement for GlyCAM-1, an endothelial ligand for L-selectin. Nature (Lond.). 361:555557.

21. Lasky, L. A., M. S. Singer, D. Dowbenko, Y. Imai, W. J. Henzel, C. Grimley, C. Fennie, N. Gillett, S. R. Watson, and S. D. Rosen. 1992. An endothelial ligand for L-selectin is a novel mucin-like molecule. Cell. 69:927-938.

22. Baumhueter, S., M. S. Singer, W. Henzel, S. Hemmerich, M. Renz, S. D. Rosen, and L. A. Lasky. 1993. Binding of L-selectin to the vascular sialomucin, CD34. Science (Wash. DC). 262:436-438.

23. Hemmerich, S., E. C. Butcher, and S. D. Rosen. 1994. Sulfation-dependent recognition of HEV-ligands by L-selectin and MECA 79, an adhesionblocking mAb. J. Exp. Med. 180:2219-2226.

24. Dowbenko, D., A. Kikuta, C. Fennie, N. Gillett, and L. A. Lasky. 1993. Glycosylation-dependent cell adhesion molecule 1 (GlyCAM-1) mucin is expressed by lactating mammary gland epithelial cells and is present in milk. $J$. Clin. Invest. 92:952-960.

25. Baumhueter, S., N. Dybdal, C. Kyle, and L. Lasky. 1994. Global vascular expression of murine CD34, a sialomucin-like endothelial ligand for L-selectin. Blood. 84:2554-2565.

26. Greaves, M. F., J. Brown, H. V. Molgaard, N. K. Spurr, D. Robertson, D. Delia, and D. R. Sutherland. 1992. Molecular features of CD34: a hemopoietic progenitor cell-associated molecule. Leukemia. 6:31-36.

27. Hamann, A., D. P. Andrew, D. Jablonski-Westrich, B. Holzmann, and E. C. Butcher. 1994. Role of $\alpha 4$-integrins in lymphocyte homing to mucosal tissues in vivo. J. Immunol. 152:3282-3293.

28. Mackay, C. R., W. Marston, and E. Dudler. 1992. Altered patterns of $\mathrm{T}$ cell migration through lymph nodes and skin following antigen challenge. Eur. J. Immunol. 22:2205-2210.

29. Michie, S. A., P. R. Streeter, P. A. Bolt, E. C. Butcher, and L. J. Picker. 1993. The human peripheral lymph node vascular addressin. Am. J. Pathol. 143: 1688-1698.

30. Faveeuw, C., M. C. Gagnerault, and F. Lepault. 1994. Expression of homing and adhesion molecules in infiltrated islets of Langerhans and salivary glands of nonobese diabetic mice. J. Immunol. 152:5969-5978.

31. Wogensen, L., X. Huang, and N. Sarvetnick. 1993. Leukocyte extravasation into the pancreatic tissue in transgenic mice expressing interleukin-10 in the islets of Langerhans. J. Exp. Med. 178:175-185.

32. Lee, M.-S., and N. Sarvetnick. 1994. Induction of vascular addressins and adhesion molecules in the pancreas of IFN $\gamma$ transgenic mice. J. Immunol. $152: 4597-4603$.

33. Salmi, M., K. Granfors, R. MacDermott, and S. Jalkanen. 1994. Aberrant binding of lamina propria lymphocytes to vascular endothelium in inflammatory bowel diseases. Gastroenterology. 106:596-605.

34. Yang, X.-D., N. Karin, R. Tisch, L. Steinman, and H. O. McDevitt. 1993. Inhibition of insulitis and prevention of diabetes in nonobese diabetic mice by blocking L-selectin and very late antigen 4 adhesion receptors. Proc. Natl. Acad. Sci. USA. 90:10494-10498.

35. Lawrence, M. B., and T. A. Springer. 1991. Leukocytes roll on a selectin at physiologic flow rates: distinction from and prerequisite for adhesion through integrins. Cell. 65:859-873.

36. Andrew, D. P., C. Berlin, S. Honda, T. Yoshino, A. Hamann, B. Holzmann, P. J. Kilshaw, and E. C. Butcher. 1994. Distinct but overlapping epitopes are involved in $\alpha 4 \beta 7$-mediated adhesion to vascular cell adhesion molecule- 1 , mucosal addressin-1, fibronectin, and lymphocyte aggregation. J. Immunol. 153: $3847-3861$.

37. Muller, W. A. 1995. The role of PECAM-1 (CD31) in leukocyte emigration: studies in vitro and in vivo. J. Leukocyte Biol. 57:523-528.

38. Carlos, T. M., and J. M. Harlan. 1994. Leukocyte-endothelial adhesion molecules. Blood. 84:2068-2101. 
39. Springer, T. A. 1994. Traffic signals for lymphocyte recirculation and leukocyte emigration: the multistep paradigm. Cell. 76:301-314.

40. Albelda, S. M., C. W. Smith, and P. A. Ward. 1994. Adhesion molecules and inflammatory injury. FASEB (Fed. Am. Soc. Exp. Biol.) J. 8:504-512.

41. Hanahan, D. 1985. Heritable formation of pancreatic $\beta$-cell tumours in transgenic mice expressing recombinant insulin/simian virus 40 oncogenes. $\mathrm{Na}$ ture (Lond.). 315:115-122.

42. Adams, T. E., S. Alpert, and D. Hanahan. 1987. Non-tolerance and autoantibodies to a transgenic self antigen expressed in pancreatic $\beta$ cells. Nature (Lond.). 325:223-228.

43. Alpert, S., D. Hanahan, and G. Teitelman. 1988. Hybrid insulin genes reveal a developmental lineage for pancreatic cells and imply a relationship with neurons. Cell. 53:295-308.

44. Skowronski, J., C. Jolicoeur, S. Alpert, and D. Hanahan. 1990. Determinants of the B-cell response against a transgenic autoantigen. Proc. Natl. Acad. Sci. USA. 87:7487-7491.

45. Grant, S. G. N., J. Jessee, F. R. Bloom, and D. Hanahan. 1990. Differential plasmid rescue from transgenic mouse DNAs into Escherichia coli methylation-restriction mutants. Proc. Natl. Acad. Sci. USA. 87:4645-4649.

46. Watson, S. R., Y. Imai, C. Fennie, J. S. Geoffroy, S. D. Rosen, and L. A. Lasky. 1990. A homing receptor-IgG chimera as a probe for adhesive ligands of lymph node high endothelial venules. J. Cell Biol. 110:2221-2229.

47. Norgard, K. E., H. Han, L. Powell, M. Kriegler, A. Varki, and N. M. Varki. 1993. Enhanced interaction of L-selectin with the high endothelial venule ligand via selectively oxidized sialic acids. Proc. Natl. Acad. Sci. USA. 90:1068-1072.

48. Gotoh, M., T. Maki, T. Kiyoizumi, S. Satomi, and A. P. Monaco. 1985. An improved method for isolation of mouse pancreatic islets. Transplantation (Baltimore). 40:437-438.

49. Chomczynski, P., and N. Sacchi. 1987. Single-step method of RNA isolation by acid guanidinium thiocyanate-phenol-chloroform extraction. Anal. Biochem. 162:156-159.
50. Sambrook, J., E. F. Fritsch, and T. Maniatis. 1989. Molecular Cloning: A Laboratory Manual. Cold Spring Harbor Laboratory, Cold Spring Harbor, NY.

51. Laemmli, U. K. 1970. Cleavage of structural proteins during the assembly of the head of bacteriophage $\mathrm{T}_{4}$. Nature (Lond.). 227:680-685.

52. Harlow, E., and D. Lane. 1988. Antibodies: A Laboratory Manual. Cold Spring Harbor Laboratory. Cold Spring Harbor, NY.

53. Folkman, J., K. Watson, D. Ingber, and D. Hanahan. 1989. Induction of angiogenesis during the transition from hyperplasia to neoplasia. Nature (Lond.). 339:58-61.

54. Kikuta, A., and S. D. Rosen. 1994. Localization of ligands for L-selectin in mouse peripheral lymph node high endothelial cells by colloidal gold conjugates. Blood. 84:3766-3775.

55. Norgard-Sumnicht, K. E., N. M. Varki, and A. Varki. 1993. Calciumdependent heparin-like ligands for L-selectin in nonlymphoid endothelial cells. Science (Wash. DC). 261:480-483.

56. Hendriks, H. R., and I. L. Eestermans. 1983. Disappearance and reappearance of high endothelial venules and immigrating lymphocytes in lymph nodes deprived of afferent lymphatic vessels: a possible regulatory role of macrophages in lymphocyte migration. Eur. J. Immunol. 13:663-669.

57. Hendriks, H. R., and I. L. Eestermans. 1987. Rapid decrease in lymphocyte adherence to high endothelial venules in lymph nodes deprived of afferent lymphatic vessels. Eur. J. Immunol. 17:1691-1695.

58. Mebius, R. E., D. Dowbenko, A. Williams, C. Fennie, L. A. Lasky, and S. R. Watson. 1993. Expression of GlyCAM-1, an endothelial ligand for L-selectin, is affected by afferent lymphatic flow. J. Immunol. 151:6769-6776.

59. Förster, I., R. Hirose, J. M. Arbeit, B. E. Clausen, and D. Hanahan. 1995. Limited capacity for tolerization of CD4+ T cells specific for a pancreatic beta cell neo-antigen. Immunity. 2:573-585.

60. Piali, L., A. Fichtel, H. J. Terge, B. A. Imhof, and R. H. Gisler. 1995. Endothelial vascular cell adhesion molecule 1 expression is suppressed by melanoma and carcinoma. J. Exp. Med. 181:811-816. 